\title{
Parental views on acute otitis media (AOM) and its therapy in children - results of an exploratory survey in German childcare facilities
}

Sibylle Kautz-Freimuth ${ }^{1 *}$, Marcus Redaèlli ${ }^{1,2}$, Christina Samel ${ }^{1}$, Daniele Civello ${ }^{1}$, Sibel V. Altin ${ }^{1}$ and Stephanie Stock

\begin{abstract}
Background: Acute otitis media (AOM) is one of the main reasons for medical consultation and antibiotic use during childhood. Although $80 \%$ of AOM cases are self-limiting, antibiotic prescription is still high, either for physician- or for parent-related factors. This study aims to identify parental knowledge about, beliefs and attitudes towards, and experiences with $\mathrm{AOM}$ and its therapy and thus to gain insights into parents' perspectives within the German health care system.
\end{abstract}

Methods: An exploratory survey was conducted among German-speaking parents of children aged 2 to 7 years who sent their children to a childcare facility. Childcare facilities were recruited by convenience sampling in different urban and rural sites in Germany, and all parents with children at those facilities were invited to participate. Data were evaluated using descriptive statistical analyses.

Results: One-hundred-thirty-eight parents participated. Of those, $75.4 \%(n=104)$ were AOM-experienced and $75.4 \%(n=104)$ had two or more children. Sixty-six percent generally agree that bacteria cause AOM. $20.2 \%$ generally agree that viruses cause AOM. $30.5 \%$ do not generally agree that viruses cause AOM. Eight percent generally agree that AOM resolves spontaneously, whereas $53.6 \%$ do not generally agree. $92.5 \%$ generally (45.7\%) and partly (42.8\%) agree that AOM needs antibiotic treatment. With respect to antibiotic effects, $56.6 \%$ generally agree that antibiotics rapidly relieve earache. $60.1 \%$ generally agree that antibiotics affect the gastrointestinal tract and $77.5 \%$ generally agree that antibiotics possibly become ineffective after frequent use. About $40 \%$ generally support and about $40 \%$ generally reject a "wait-and-see" strategy for AOM treatment. Parental-reported experiences reveal that antibiotics are by far more often prescribed (70.2 \%) than actively requested by parents (26.9\%).

Conclusions: Parental views on AOM, its therapy, and antibiotic effects reveal uncertainties especially with respect to causes, the natural course of the disease and antibiotic effects on AOM. These results indicate that more evidence-based information is needed if parents' health literacy in the treatment of children with AOM is to be enhanced. The discrepancy between reported parental requests for antibiotics and reported actual prescriptions contradicts the hypothesis of high parental influence on antibiotic use in AOM.

Keywords: Acute otitis media in children, Antibiotic treatment, Exploratory survey, Pediatrics, Health service research, Parental views

\footnotetext{
* Correspondence: sibylle.kautz-freimuth@uk-koeln.de

${ }^{1}$ Institute of Health Economics and Clinical Epidemiology, University Hospital

of Cologne (AöR), Gleueler Straße 176-178, 50935 Cologne, Germany

Full list of author information is available at the end of the article
}

C Biomed Central (c) 2015 Kautz-Freimuth et al. Open Access This article is distributed under the terms of the Creative Commons Attribution 4.0 International License (http://creativecommons.org/licenses/by/4.0/), which permits unrestricted use, distribution, and reproduction in any medium, provided you give appropriate credit to the original author(s) and the source, provide a link to the Creative Commons license, and indicate if changes were made. The Creative Commons Public Domain Dedication waiver (http://creativecommons.org/publicdomain/zero/1.0/) applies to the data made available in this article, unless otherwise stated. 


\section{Background}

Acute otitis media (AOM) is one of the most common infectious diseases in young children and represents one of the main reasons for doctor consultations during childhood [1]. In addition AOM is the leading cause of antibiotic treatment in children [2-4]. According to data from the USA, around 50 to $85 \%$ of all children up to the age of three have had at least one episode of AOM $[5,6]$ and about $40 \%$ have experienced six or more episodes by the age of seven [6]. According to the German Health Interview and Examination Survey for Children and Adolescents (KIGGS) the 12-month prevalence of AOM across all age groups is $11 \%$ and rises to $22.9 \%$ between the ages of 3 and 6 years [7]. AOM can be caused by bacteria or viruses as well as by mixed pathophysiological mechanisms [8-12]. The bacterial pathogens mostly involved in AOM development are Streptococcus pneumonia, Haemophilus influenza, and Moraxella catarrhalis [13], but it has been suggested that the spectrum of predominant bacterial pathogens responsible for AOM might change due to previous antibiotic prescriptions [13] or to pneumococcal vaccination $[14,15]$. AOM episodes typically occur subsequent to a viral upper respiratory infection, but the underlying mechanisms for the interaction between the different pathogens are still being investigated [9]. Despite the frequent involvement of bacteria in the pathogenesis of $\mathrm{AOM}$, an antibiotic treatment is not imperative, with research showing that $80 \%$ of uncomplicated AOM cases in children resolve spontaneously within 48 to $72 \mathrm{~h}$ without antibiotic therapy [16]. Nevertheless, data from the USA and other countries indicate that up to $80 \%$ of medical consultations due to otitis media in children still result in an antibiotic prescription $[4,17,18]$.

In the light of the rising prevalence of antibiotic resistance in bacteria [19], the arguments in favour of reducing antibiotic overuse/misuse are compelling. One decisive approach is to avoid antibiotics if not indicated or not superior to symptomatic treatment. A Cochrane Review has recently demonstrated that immediate antibiotic therapy in children with AOM is not superior to an observational therapy ("wait-and-see") [20]; a therapy where children receive symptomatic analgesic treatment and an antibiotic is not given unless symptoms fail to improve within 48 to $72 \mathrm{~h}$ after onset [21]. Currently there is a broad consensus that antibiotics are most beneficial in children younger than 2 years of age with bilateral AOM, and in children with both acute otitis media and otorrhoea [20, 22]. For most other children with mild unilateral AOM, an observational approach seems justified [22-25]. Despite this existing evidence for this strategy the proportion of antibiotic treatment in children with AOM is still high [26]. Possible reasons for physicians over-prescribing antibiotics include physician inertia, lack of detailed knowledge, insufficient use of appropriate analgesia or uncertain diagnosis [27]. With respect to parental influence on the prescription of antibiotics, there is evidence that parental perspectives can indeed have a marked influence on therapeutic decisions [28, 29], and for AOM a certain proportion of parents actively demand antibiotics [30]. Additionally, perceived parental expectations have been identified as one determinant in antibiotic prescription through pediatricians [29,31]. Prior studies indicate that parental socio-demographic factors, such as educational level, age, or having more than one child can affect parental knowledge and attitudes towards AOM and its therapy $[30,32]$ and thus might also be relevant. It has been shown that the use of shared decision-making (SDM) in medical consultation is highly influenced by the parental health literacy level, indicating that limited health literacy facilitates a patriarchal relationship between physicians and parents and increases the tendency to follow physician recommendations [33]. Moreover, there is evidence that SDM may lead to less antibiotic prescription and higher levels of parental satisfaction in the treatment of AOM [34]. Therefore, supporting parent-physician interaction and promoting understanding between parents and physicians seems a promising approach to enhancing rational antibiotic prescription in children with AOM.

The aim of this study is to identify parental knowledge, beliefs, attitudes, and experiences with regard to AOM and its therapy and thus to gain initial insights into parental perspectives within the German health care system and to provide a better understanding of non-medical determinants of therapeutic decisions, which may help to enhance SDM in the treatment of children with AOM. We hypothesize that parental knowledge with regard to causes of AOM, best treatment of earache and effects of antibiotics is fairly limited. We further hypothesize that the high use of antibiotic in children with AOM is due to parental preference for antibiotics rather than for nonantibiotic options or a "wait-and-see" strategy. Finally, we hypothesize that parent-related factors such as previous AOM-experience or socio-demographics, do have an impact on decisions related to AOM therapy. By analyzing these research questions, we aim to contribute valuable insights to the ongoing discussion in health services research on whether the parents or the health care professionals are the ones preferring or demanding specific treatment options, especially the use of antibiotics.

\section{Methods}

\section{Study design, participants and setting}

An exploratory survey among German-speaking parents of children aged 2 to 7 years was conducted between January and October 2013. To reach this target group, we recruited childcare facilities by convenience sampling at different sites in the western part of Germany aiming 
to involve facilities with different pedagogical concepts and thus address a wider spectrum of parent types. The childcare facilities were located in seven towns with population sizes ranging from cities over a million inhabitants to medium-sized towns with 20,000 to 100,000 inhabitants. Five childcare facilities were situated in more rural settings and ten in urban settings. All parents connected to the addressed childcare facilities were invited to participate in the survey. A questionnaire with a cover letter explaining the study objective was distributed to each parent's pigeonhole in the childcare facility. Only one parent per family was supposed to fill in the questionnaire, even if several children from that family attended the same childcare facility. Parents were asked to return the questionnaire anonymously in a sealed box, which was not opened until data capture and analysis commenced. All childcare facilities had given consent to their participation and distributed questionnaires to the parents. In the specified time period 15 childcare facilities could be recruited, and overall, 710 parents were addressed. As there were no comparable studies available that examined our research questions in a German sample, a middle-sized effect for calculating correlations was assumed, which lead to a minimal number of 107 parents to be questioned $[35,36]$. By the end of the recruiting time a sample size of 138 parents representing a total of 278 children was achieved.

\section{Questionnaire development}

To determine the content and structure of the questionnaire a qualitative approach was chosen derived from a concept that was developed by Jónsson and Haraldsson in 2002 [37]. According to their 'parents' explanatory model" there are three issues that mainly influence parents' perspectives on AOM in their children: (1) perceptions on the causes of AOM, (2) ideas on disease threats due to AOM, and (3) attitudes towards the treatment of AOM (e.g. use of antibiotics). Additionally, we expanded the domains by conducting a literature search to identify AOM-related factors that account for parental knowledge/beliefs, attitudes, and experiences in more detail. To develop the questionnaire, we used these domains as a structural and textual basis and derived an expanded model by discussing the structure of the questionnaire in an expert group consisting of physicians, nurses, health economists, and parents. The aim of the brainstorming was to identify and contextualize topics related to parental knowledge, beliefs, attitudes and experiences related to AOM in children. Eligible domains were then operationalized in a structured discussion process between the experts.

The questionnaire was then revised based on the discussion results and pilot-tested in a two-phase pretest to verify its clarity, comprehensibility and practicability.
Testing was performed using the concurrent-thinkaloud-method with six participants [38-40] followed by standard pretests with eight volunteers [41]. The final content structure of the questionnaire is presented in Table 1.

The questionnaire consisted of 15 domains with a total of 53 items. A translated English version is accessible in Additional file 1. Each domain consisted of one question with between one and seven corresponding items. Eleven of the domains, with a total of 47 items, referred to aspects of knowledge, attitudes and experiences. They were formulated as closed questions. Eight of them used a five-point Likert rating scale [42], the three remaining domains used categorical scales. The five-point Likert scale (levels of agreement: from "fully agree" to "don't agree at all") was chosen to allow for gradual classification of respondents' opinions [43, 44]. All items concerning knowledge had the additional answer option "don't know". Two domains referring to respondents' experiences used a five-point Likert scale for frequency (from "always" to "never"). We calculated the descriptive analyses by building the following categories: "generally agree", "partly agree", "do not generally agree" or "always/often", "sometimes", "rarely/never". Four domains used categorical scales to record answers on sociodemographic data. Two domains addressed the current age of the respondents and their children by asking the respondents to record the respective ages. Multiple answers were not permitted in any domain.

\section{Data analysis}

The questionnaires were scanned and then processed using Remark Office OMR ${ }^{\mathrm{in}}$ Version 8. A random portion of $20 \%$ of the questionnaires was manually checked for scanning errors. The data were then transferred to IBM SPSS Statistics version 21 for statistical analysis. Descriptives were performed using frequencies and counts, contingency tables were evaluated using Fisher's

Table 1 AOM-related topics used in the questionnaire

Parental knowledge/beliefs about AOM

- Causes of AOM

- Symptoms of AOM

- Course of the disease

- Treatment options

- Effects of antibiotics

Parental attitudes towards AOM treatment

- Importance of contact partners

- Relevant media for obtaining information

- Attitudes towards use of antibiotic in own child

Parental experiences with AOM treatment

- Frequency of AOM episodes

- Choice of health care practitioner

- Parental requests for treatment

- Actual doctor's prescription 
Table 2 Demographic characteristics of the respondents $(n=138)$ and their children $(n=278)$

\begin{tabular}{|c|c|c|}
\hline Respondents & $N(138)$ & Percent \\
\hline \multicolumn{3}{|l|}{ Age (years) } \\
\hline Mean \pm SD & $38.13 \pm 10.78$ & \\
\hline Median & 38 & \\
\hline Range & $26-49$ & \\
\hline \multicolumn{3}{|l|}{ Gender } \\
\hline Female & 131 & 94.9 \\
\hline Male & 7 & 5.1 \\
\hline \multicolumn{3}{|l|}{ Education (degree) } \\
\hline Middle school certification & 4 & 2.9 \\
\hline Intermediate high school certification & 23 & 16.7 \\
\hline Final high school certification & 37 & 26.8 \\
\hline University degree & 73 & 52.9 \\
\hline \multicolumn{3}{|l|}{ Living environment } \\
\hline Urban & 86 & 62.3 \\
\hline Rural & 50 & 36.2 \\
\hline \multicolumn{3}{|l|}{ Single parent } \\
\hline Yes & 7 & 5.1 \\
\hline No & 125 & 90.6 \\
\hline \multicolumn{3}{|l|}{ Number of children (per parent) } \\
\hline 1 child & 34 & 24.6 \\
\hline 2 children & 72 & 52.2 \\
\hline 3 children & 28 & 20.3 \\
\hline 4 children & 4 & 2.9 \\
\hline \multicolumn{3}{|l|}{ Experience with $\mathrm{AOM}$ in own child } \\
\hline Yes & 104 & 75.4 \\
\hline No & 33 & 23.9 \\
\hline Respondents with AOM experience & $N(104)$ & $\%$ \\
\hline \multicolumn{3}{|l|}{ Number of AOM episodes } \\
\hline$<3$ times & 43 & 41.4 \\
\hline 3-10 times & 51 & 49.0 \\
\hline$>10$ times & 10 & 9.6 \\
\hline \multicolumn{3}{|l|}{ Health service utilization in AOM } \\
\hline Pediatrician & 63 & 60.6 \\
\hline General practitioner & 3 & 2.9 \\
\hline ENT specialist & 7 & 6.7 \\
\hline First aid pediatrician service & 4 & 3.8 \\
\hline Emergency service in hospital & 3 & 2.9 \\
\hline Not answered & 24 & 23.1 \\
\hline Children (of all respondents) & N (278) & $\%$ \\
\hline \multicolumn{3}{|l|}{ Children's age (years, $n=278$ ) } \\
\hline $0-1$ year & 27 & 9.7 \\
\hline $2-7$ years & 195 & 70.1 \\
\hline $8-17$ years & 53 & 19.1 \\
\hline
\end{tabular}

Table 2 Demographic characteristics of the respondents $(n=138)$ and their children $(n=278)$ (Continued)

\begin{tabular}{lll}
\hline 18 years and older & 3 & 1.1 \\
Mean \pm SD (years) & $5.37 \pm 3.55$ & \\
Median (years) & 5 & \\
Children's health insurance $(n=278)$ & & \\
Statutory & 187 & 67.3 \\
Private & 81 & 29.1 \\
\hline
\end{tabular}

exact test. Since prior studies indicate that there are sociodemographic determinants of parental AOM knowledge and attitudes, correlations were calculated using-where applicable-Pearson's correlation coefficient, and for categorical data Spearman's rho. To adjust for multiple testing, the Bonferroni-Holm method was applied to control for the familywise error rate.

As a guiding measure for overall parental experience on children's health the group of parents with two or more children ("several-child parents") was compared to the group of parents with one child ("single-child parents"). The hypothesis that "several-child parents" are more experienced in children's health is supported in a study by Aku-Baker et al., who reported a significant correlation between the number of children and the mothers' knowledge and ability to cope with fever in their child [45].

\section{Ethical considerations}

The study was a survey involving questionnaires. Participation was voluntary and anonymous collection and data analysis was guaranteed through anonymous questioning, questionnaire collection, and analysis. All participants gave consent for the results to be published. In a prestudy consultation with the ethic committee of the University Hospital of Cologne, we were advised that an approval through the ethics committee was not necessary.

\section{Results}

\section{Distribution of questionnaires and response rate}

The complete number of distributed questionnaires $(n=710)$ corresponded exactly to the number of families with at least one child in the participating childcare facilities. In total, 138 questionnaires were returned, which results in a response rate of $19.4 \%$. These questionnaires were included in the data analysis.

\section{Socio-demographic data}

Table 2 summarizes the socio-demographic characteristics of the respondents $(n=138)$ and their children $(n=278)$. The majority of children (70.14\%) were aged between 2 and 7 years representing the main age category of interest 
for our survey. All but two respondents had at least one child within this age span.

\section{Parental knowledge/beliefs about AOM, treatment of earache and effects of antibiotics}

Aspects of knowledge and beliefs on AOM, treatment of earache in AOM, and effects of antibiotics in AOM were surveyed using 19 items. The results are presented in Fig. 1. For the cause of AOM, $66 \%$ of all respondents generally agree that bacteria cause AOM. $20.2 \%$ generally agree that viruses cause AOM. $30.5 \%$ do not generally agree that viruses cause AOM. A relatively high proportion of respondents states not to knowing the cause (11.6\% for bacteria, $15.9 \%$ for viruses), and 4.3 and $10.9 \%$, respectively, do not answer. The view that AOM is caused by viruses meets significantly less approval from parents with increasing age $(p<0.05)$, with AOM experience $(p<0.05)$, who live in an urban environment $(p<0.05)$, and who are single parents $(p<0.05)$. Concerning symptoms, $92.7 \%$ of the parents generally agree that intensive earache is associated with AOM, and $53.4 \%$ generally agree that fever is part of AOM. With respect to the course of the disease, $8 \%$ generally agree that AOM resolves spontaneously, whereas $53.6 \%$ do not generally agree. This view is confirmed by $92.5 \%$ of the respondents, who generally $(45.7 \%)$ and partly (42.8\%) agree that AOM needs antibiotic treatment.

Most of the parents consider analgesic/antipyretic drugs (71 \%) and nasal drops with decongestant $(68.8 \%)$ as being the best treatment for earache (generally agree), but $52.1 \%$ view antibiotics as being the best therapy (generally agree). There is no clear preference for other treatments (household remedies, naturopathic remedies, eardrops), and a relatively high proportion of parents do not know (11.6, 10.2, $16.7 \%$, respectively). $3.6,5.8,4.3 \%$, respectively, refuse to answer. With regard to antibiotic effects, $56.6 \%$ generally agree that antibiotics lead to rapid pain relief and $46.6 \%$ generally agree that they lead to rapid fever reduction. $8.7 \%$ generally agree that they reduce AOM relapse, whereas $65.2 \%$ do not generally agree. A risk-reducing effect on permanent ear damage is generally affirmed by 40.6 and $26.1 \%$ do not know or do not answer. Concerning undesired effects, the majority generally agrees that antibiotics affect the gastrointestinal tract (60.1\%) and possibly become ineffective after frequent use (77.5 \%). Parents holding a university degree believe significantly less often than those without a university

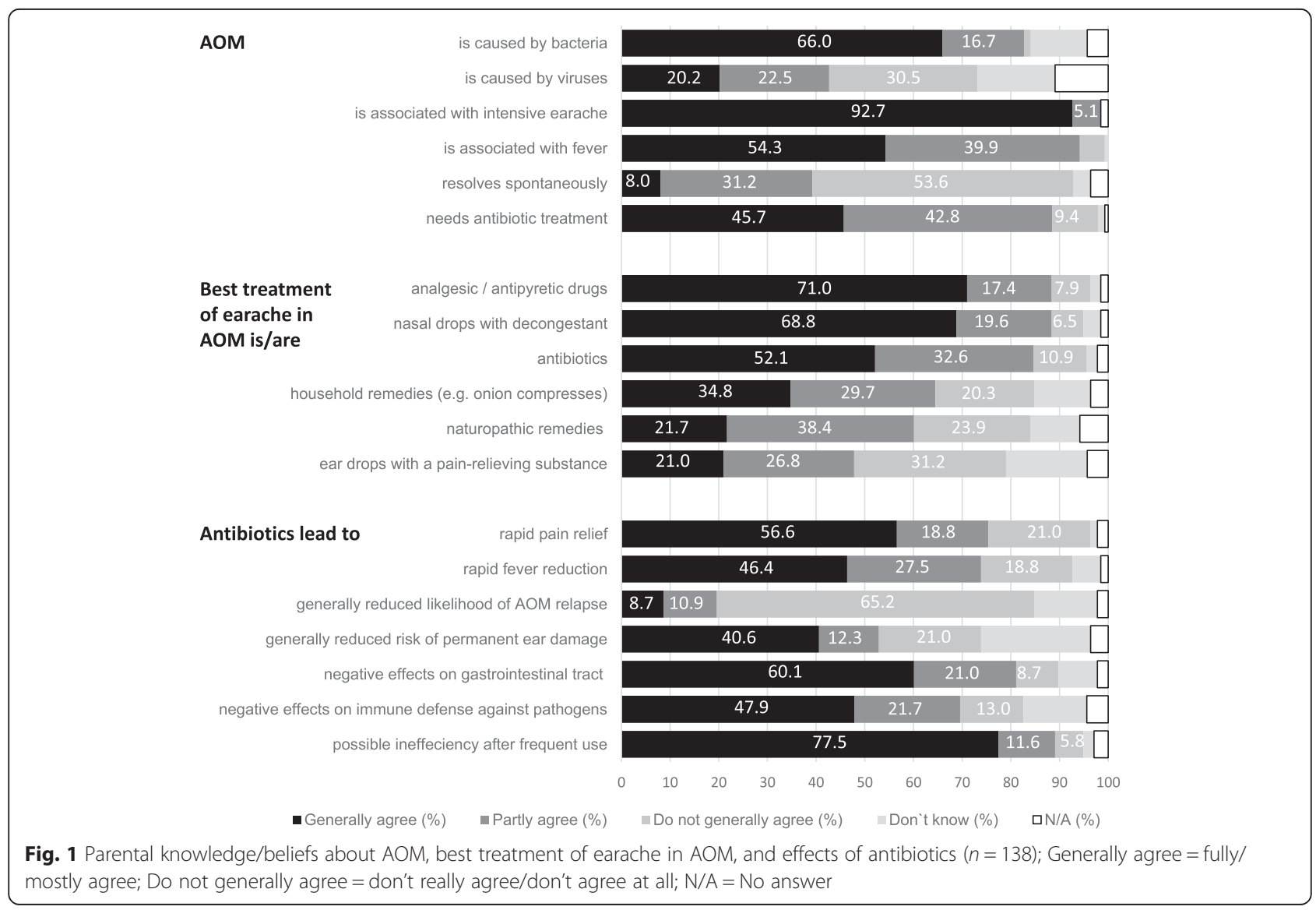


degree that antibiotics negatively affect the gastrointestinal tract $(p<0.05)$ and become inefficient after frequent use $(p<0.05)$.

\section{Parental attitudes towards AOM treatment of their own child}

Three domains consisting of 15 items asked for parental attitudes concerning the treatment of AOM. On the topic of the relevance of contact partners, $89.9 \%$ of the respondents see the pediatrician's opinion as being of great importance (generally agree), whereas $37.7 \%$ rate the family doctor's opinion being greatly important (generally agree). Close relatives, other parents, teachers in child-care centers and friends who are health care professionals are mainly rated as being of partly, little or no importance. Among the sources of information, the internet takes the first place $(46.4 \%$ generally very helpful), followed by books (33.3 \% generally very helpful). Radio, television, newspapers and magazines are of little importance.

One domain involving five items addresses parental attitudes towards their willingness to follow a "wait-andsee" strategy in their child with AOM (Table 3). Almost $40 \%$ of the respondents generally agree with not using antibiotics until symptoms persist for 2 days (39.1\%) or worsen overnight (38.4\%). Around the same proportion does not generally agree to delay antibiotic therapy for 2 days $(43.5 \%)$ or in case of severe symptoms (44.2\%). In the latter case, "several-child parents" would rather give an antibiotic compared to "single-child parents" $(p<0.01)$. In contrast, $32.6 \%$ of parents generally agree to wait even if the child severely suffers. Previous AOM-experience does not affect this attitude; neither do any of the demographic factors (age, education, living environment).

\section{Parental experiences with $\mathrm{AOM}$ treatment}

Four domains including 12 items refer to parental experiences with respect to medical treatment of AOM. This part of the survey only includes respondents who had experienced at least one episode of AOM in their child
( $n=104,75.4 \%)$. Forty-three parents have seen less than three episodes, 61 three or more. In this situation, $60.6 \%$ consulted their pediatrician. $23.1 \%(n=24)$ gave no answer.

Two domains address the questions as to what kind of medical therapy parents wished to have prescribed for their child with AOM and what therapy was actually prescribed by the doctor (Fig. 2). Most often parents ask for nasal drops with decongestant $(62.5 \%)$ and analgesic/antipyretic drugs $(55.8 \%)$. Corresponding actual prescriptions are $81.7 \%$ for nasal drops and $80.7 \%$ for analgesic/antipyretic drugs, which turns out to be the same tendency but to a higher extent compared to parental requests. Parental requests for naturopathic drugs and eardrops with a pain-relieving substance are relatively rare and the same tendencies are found with respect to the corresponding actual prescriptions.

Comparing the rates of parental requests and actual prescription of antibiotics, we find a striking discrepancy: While only $26.9 \%$ of the parents state having always/often asked for an antibiotic, $70.2 \%$ state that their child was always/often prescribed one. On the other hand, $58.7 \%$ report having rarely/never asked for an antibiotic, while only $15.4 \%$ state having rarely/never received a prescription. $96.4 \%$ of the parents who have always/often asked for an antibiotic $(n=28)$, always/often received a prescription for one, whereas $65 \%$ of the parents who rarely/never asked for an antibiotic $(n=60)$ always/often received a prescription for one.

We evaluated possible differences concerning knowledge and attitudes between parents who wished for an antibiotic and those who did not by comparing the answer categories "always/often/sometimes/rarely" $(n=63)$ to the category "never" $(n=41)$ : Compared to parents who never asked for an antibiotic, parents who did wish for one for their child agree more often that antibiotics are the best therapy for earache in AOM $(p<0.05)$ and lead to rapid pain relief $(p<0.05)$. In addition, they disagree more often with the statement that antibiotics negatively affect the infantile gastrointestinal flora $(p<0.05)$

Table 3 Parental willingness to follow a "wait-and-see" strategy in their child with AOM $(n=138)$

\begin{tabular}{|c|c|c|c|c|}
\hline \multirow[t]{2}{*}{ Willingness to wait $^{\mathrm{a}}$} & \multicolumn{4}{|c|}{ Level of agreement (\%) } \\
\hline & Generally agree & Partly agree & Do not generally agree & No answer \\
\hline Yes; use of antibiotics only when symptoms persist for 2 days & 39.1 & 12.3 & 43.5 & 5.1 \\
\hline Yes; use of antibiotics only when symptoms worsen overnight & 38.4 & 23.2 & 33.3 & 5.1 \\
\hline Yes; consult the doctor again when symptoms worsen & 27.6 & 13 & 55.1 & 4.3 \\
\hline No; immediate use of antibiotics when child experiences severe symptoms & 44.2 & 18.9 & 32.6 & 4.3 \\
\hline No; immediate use of antibiotics out of concern about AOM-worsening & 25.4 & 22.5 & 47.8 & 4.3 \\
\hline
\end{tabular}

Generally agree $=$ fully $/$ mostly agree

Do not generally agree $=$ don't really agree/don't agree at all

${ }^{a}$ For better clarity the patterns of behavior are presented in a shortened version 


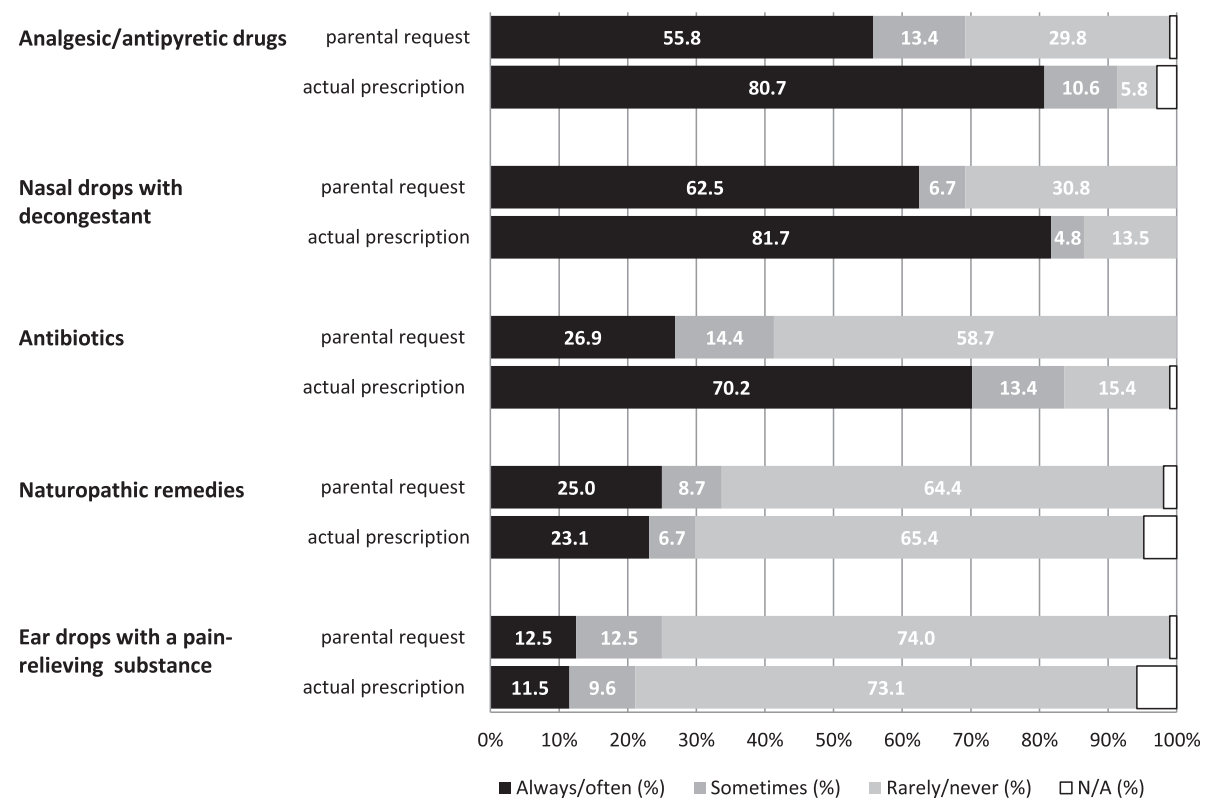

Fig. 2 Percentages of parental requests for therapeutic agents for their child with $A O M$ and reported actual prescriptions ( $n=104)$; $\mathrm{N} / \mathrm{A}=$ No answer

and have less faith in household remedies for treating earache $(p<0.05)$. Knowledge concerning cause, symptoms and course of the disease does not differ between the two groups.

\section{Impact of parental experience of AOM and children's health}

To assess the impact of experience with AOM on parental knowledge and attitudes the answers of AOMexperienced parents $(n=104)$ were compared to those of non-AOM experienced parents $(n=34)$. Only one in a total of 34 related items in this comparison differs significantly: Compared to non-AOM-experienced parents, AOM-experienced parents agree less often with the statement that AOM is caused by viruses $(p<0.05)$.

To investigate the influence of the number of children per family on the parental responses concerning knowledge/beliefs, attitudes, and experiences the group of "several-child parents" ( $n=104)$ was compared to the group of "single-child parents" $(n=34)$. Compared to "single-child parents", "several-child parents" significantly more often consider bacteria to cause AOM $(p<0.05)$ and nasal drops with decongestant $(p<0.05)$ and naturopathic remedies $(p<0.05)$ to be the best treatment for earache. However, they agree significantly less often that AOM is associated with fever $(p<0.05)$ and that antibiotics are the best therapy for earache $(p<0.05)$. For "several-child parents" close relatives $(p<0.05)$, other parents $(p<0.01)$, and teachers in child-care facilities $(p<0.01)$ are significantly less important as contact partners concerning AOM treatment in their child. Regarding the "wait-and-see" strategy, "several-child parents" agree considerably more often to wait and consult the doctor again, when symptoms worsen $(p<0.05)$ before giving an antibiotic. However, in comparison to the "single-child parents" they would rather immediately give an antibiotic $(p<0.01)$ when severe symptoms are present right from the beginning. Regarding their requests for medical prescriptions for their child with AOM they do not differ from "single-child parents".

\section{Discussion}

The aim of our study is to elicit parental knowledge/beliefs, attitudes, and experiences on AOM and its treatment in the German health care context. In general, the results provide first insights on how parents might think about AOM and experience AOM and its treatment within the German health care system. With respect to knowledge/beliefs about AOM, parental answers indicate a realistic view of key symptoms but show uncertainties regarding underlying causes and the natural course of the disease. Knowledge about antibiotics reveals misconceptions regarding effectiveness in AOM treatment and a more realistic view on undesired effects. Around $40 \%$ of all parents are generally willing to follow a "wait-andsee" strategy, but for severe symptoms, around the same portion generally prefers the immediate use of an antibiotic. Experiences with AOM therapy show that parental request rates for antibiotic treatment strongly differ from the reported rates of actual prescription, indicating that antibiotics are around three times more likely to be prescribed for children with AOM than expected by the parents. 


\section{Parental knowledge/beliefs about AOM, treatment of earache and effects of antibiotics}

The present results indicate that parents seem to have a fairly realistic view of key symptoms of the disease, as the $92.7 \%$ generally agree that earache is associated with $\mathrm{AOM}$ and $54.3 \%$ generally agree that fever is part of AOM. Uncertainties exist concerning causes and the natural course of the disease. Sixty-six percent of the parents generally agree that bacteria cause AOM, whereas $20.1 \%$ generally agree that viruses cause AOM. $30.5 \%$ do not generally agree that viruses cause AOM. A relatively high proportion states not to knowing the cause (11.6\% for bacteria, $15.9 \%$ for viruses), and 4.3 and $10.9 \%$, respectively, do not answer. Thus, the fact that viruses are mostly involved in the pathophysiological mechanisms of AOM $[46,47]$ does not seem to be widely known. AOM-experienced parents significantly less often believe viruses to be involved than nonAOM-experienced parents. Given the fact that parents know well that antibiotics are effective against bacteria $[48,49]$, these findings might reflect the experiences of $70.2 \%$ of the AOM-experienced parents in our sample that their child with AOM has previously been treated with an antibiotic. The reported proportion of antibiotic prescriptions in our sample largely corresponds to findings of other authors [50,51].

Special emphasis should be placed on the parental perception towards the natural course of AOM and the need for antibiotics. Only $8 \%$ of the respondents in the present survey generally agree to the statement that AOM resolves spontaneously, whereas $53.6 \%$ do not generally agree. These opinions are supported by the view of 45.7 and $42.8 \%$ of the parents, who, respectively, generally and partly agree that AOM needs antibiotic treatment, which indicates that parents might considerably underestimate the self-limiting character of uncomplicated AOM in children. This assumption is also supported by a previous survey reporting a high proportion of parents who believe antibiotics are necessary when treating AOM (85 \% for Finland, $55 \%$ for The Netherlands) [52].

Most of the parents in our sample generally (45.7\%) or partly $(42.8 \%)$ agree that AOM needs antibiotic treatment and although $71 \%$ generally agree that analgesic/ antipyretic drugs are the best treatment for earache in AOM, $52.1 \%$ generally agree antibiotics are the best pain-relieving therapy in earache. The latter is in accordance to results from other authors $[49,53]$ and may be explained by the finding that $56.6 \%$ of the parents in our sample generally agree to the statement that antibiotics lead to rapid pain relief. A fast pain relief is of great importance to parents, since AOM in children gives rise to considerable burdens for the affected children as well as for their families [51, 54]. However, the expected rapid analgesic effect (within $24 \mathrm{~h}$ ) in the course of AOM treatment in children is not confirmed by a recently published Cochrane analysis [20]. This review shows that, compared to placebo, antibiotics do not lead to a significant pain reduction within $24 \mathrm{~h}$. The review also demonstrated that, compared to a placebo or watchful waiting ("wait-and-see"), antibiotics do not reduce severe complications or recurrence rate of AOM. The majority of the respondents in the present study is aware of possible harms associated with antibiotic treatment such as negative effects on the gastrointestinal tract, which actually is seen in one of every 14 antibiotic-treated children [20], or possible inefficiency after frequent use (antimicrobial resistance), which is known to be an increasingly national and international threat for general public health $[19,55]$. The high parental awareness towards the increased risk of antimicrobial resistance associated with antibiotic overuse demonstrated in the present study is consistent with results of other investigations $[49,52,56]$.

In summary, parental knowledge and beliefs concerning $\mathrm{AOM}$ and its treatment and the effects of antibiotics turn out to be heterogeneous. This might be due to miscommunication between parents and physicians. Whatever the reason, these results could serve as a basis for developing patient-centered and evidence-based information on the treatment of AOM for parents.

\section{Parental attitudes towards AOM treatment in their own child}

Our study shows that the pediatrician is the most important contact partner for parents who seek medical advice regarding the treatment of AOM. This finding is consistent with sickness fund data from Germany on the utilization of pediatricians or family doctors with sick children up to the age of seven [57]. However, our study shows two opposing trends concerning parental attitudes towards the two different AOM therapeutic concepts available for treating their child, either allowing a 2-day observational period before giving an antibiotic or preferring immediate antibiotic treatment. While almost $40 \%$ would generally accept the "wait-and-see" strategy and only give an antibiotic once symptoms have persisted for 2 days or worsened overnight, about the same percentage would not generally accept this strategy. For severe symptoms, $44.2 \%$ would immediately administer an antibiotic, whereby, compared to "single-child parents", "severalchild parents" prefer this concept $(p<0.01)$. These results indicate that around $40 \%$ of the parents might generally favor the "wait-and-see" strategy, but might prefer an immediate antibiotic use if the child is suffering greatly. This finding suggests that many parents take antibiotics as the most effective therapy compared to other options. The relatively high proportion of parents rejecting initial 
observation corresponds to the results found by Finkelstein et al. [32], who conducted a survey dealing with physicians' use of initial observation in AOM and the parental acceptance of this strategy. In contrast to our results, the investigators additionally identified an association between educational level and parental acceptance of initial observation. It should be noted that parental acceptance of initial observation can be supported when the doctor gives a brief explanation for this strategy [58]. Adherence is also enhanced when parents are instructed to seek follow-up care if the symptoms persist without receiving an additional prescription for antibiotics (with the advice to hand it in, if symptoms fail to improve) compared to not receiving a prescription [59].

\section{Parental experiences with AOM treatment}

International guidelines [22, 60,61] and recently published national overviews $[47,62]$ recommend that children aged 2 years and older with uncomplicated unilateral AOM receive initial observation including symptomatic treatment with an analgesic drug as first line therapy. An antibiotic should be added if symptoms fail to improve within 48 to $72 \mathrm{~h}$. The use of other agents, such as naturopathic remedies, eardrops with a pain-relieving substance, or nasal drops with decongestant, is not explicitly recommended.

With respect to parental requests for medical treatment and the reported actual prescriptions, we find two trends: (1) For analgesic/antipyretic drugs, nasal drops with decongestant, naturopathic remedies, and painrelieving eardrops, the rates of parental requests and actual prescriptions are in high concordance. (2) For antibiotics, there is a striking discrepancy between reported parental request rates and reported prescribing rates, indicating that antibiotics might be around three times more likely to be prescribed for children with AOM than expected by the parents. This finding contradicts the frequently expressed view that parents often put pressure on doctors to prescribe an antibiotic for their child with AOM [55]. We cannot fully exclude the possibility that there might be a recall bias especially concerning requests for antibiotics and actual antibiotic prescriptions, which is much larger than the difference found for all other treatment options. Nevertheless, in accordance with our results, other studies have also suggested that antibiotic overuse is not caused by parental pressure $[49,63]$. Based on the present results, possible reasons for the marked difference between parental request rates and doctors' prescription rates in our sample remain unclear. The relatively low parental tendency to ask for an antibiotic might have several reasons, such as having concerns about antibiotic overuse or antibiotic resistance [52, 64] or a tendency not to ask doctors for a special medication, e.g., because parents trust them and rely on their decisions [65].

From the physicians' perspective, the question arises as to why actual antibiotic prescription rates in the present study are as high as reported. It could be concluded that the "wait-and-see" strategy is applied less than could be expected based on the guideline recommendations. Determinants other than objective medical criteria, such as perceived parental expectation might play a role in antibiotic prescription $[29,63,66]$. Another reason for overuse of antibiotics may be diagnostic uncertainty resulting in over-diagnosis of AOM [27, 29, 67-69]. As Täthinen et al. suggest, treatment practices and parental expectations seem to interact [52]. Therefore to achieve a change in treatment practices, both parental views and physicians' attitudes and practices have to be addressed.

\section{Parental experience of AOM and children's health}

Our analysis demonstrates that prior experience of AOM does not influence parental knowledge and attitudes, except that AOM-experienced parents are less inclined to agree that AOM is caused by viruses. However, having two or more children (implying more general experience of children's health) is associated with significant differences compared to having a single child: "Several-child parents" regard nasal drops with decongestant and naturopathic drugs more often as being the best therapy for earache. Although they classify antibiotics less often as best pain treatment, they prefer more often immediate antibiotic use in cases of severe symptoms. Thus, general experience of children's health might have a stronger influence on parental knowledge about and attitudes to AOM and its therapy than concrete experience with AOM. This conclusion is in accordance with results from research by Kuzujanakis et al. [30], who found a significant association between having more than one child and correct parental antibiotic knowledge. However, in contrast, a recently published study that investigated parental views on childhood fever found no correlation between having more than one child and knowledge about antibiotic effectiveness on bacterial infections [70], whereas personal parents' experience with serious illness in the own child was significantly associated with more concerns about health problems related to fever. In our sample higher parental educational level is not associated with higher antibiotic knowledge. This result is in contrast to other studies that see a correlation between parental education degree and the parental antibiotic knowledge $[30,71]$, the tendency to expect or ask for an antibiotic $[30,72]$ the frequency of antibiotic prescriptions [29], and the use of antibiotics with their child [30,63]. The present data allow no clear conclusions to be drawn on the reasons for this discrepancy. 
The current findings may be of considerable relevance for several reasons: (1) The results may provide a basis for a better understanding of parental views on AOM and its therapy. To confirm these findings, further investigations with a representative parent sample of parents in Germany are called for. (2) The results give some indication of parental concepts and misconceptions on AOM and its therapy. Since decisions on treatment options may be influenced by both physicians and parents, the findings may serve as a basis for developing evidence-based information for parents to support parental health literacy and for fostering shared decision-making processes between parents and physicians. (3) The reported prescription rates of antibiotics may lead to the assumption that actual guidelines on AOM management in children, especially the option of "wait-and-see", may be used less often than could be expected. Further investigations are needed to elucidate this hypothesis.

\section{Strengths and limitations}

The main strength of this study is that it represents a first survey in Germany that investigates knowledge/beliefs, attitudes, and experiences towards AOM and its therapy in parents with children aged 2 to 7 years. While not claiming to be representative, the results provide initial insights in parental views on AOM and its treatment. Although the results do not allow generalization so far, they still might serve as a starting point for further investigations of the German population. Limitations of the survey include the small number of respondents, a low response rate and the convenience sampling strategy applied for recruiting childcare facilities. Most of the participants are female and are not single parents, and more than half of them hold a university degree. Therefore, a possible selection bias cannot be excluded. On the other hand, this selection may reflect-at least in part-an approach to a realistic depiction of the group of parents who usually deal more often with childcare. The survey may also be subject to a non-response bias, because it only includes those childcare facilities and those parents that voluntarily agreed to participate and we had no means of analyzing the non-responders. Additionally, due to the lack of data concerning the time period between the last experienced AOM and answering the questionnaire, there might be a recall bias arising from a possible time delay between experiencing the acute disease and giving statements from memory. This time delay might bias the actual experiences and expectations and influence the answers.

\section{Conclusions}

We present the results of an exploratory survey in the German health care system that investigates knowledge/ beliefs, attitudes, and experiences towards AOM and its therapy in parents with children aged 2 to 7 years. Parental knowledge and beliefs on AOM and its therapy reveal uncertainties especially with respect to underlying causes and the natural course of the disease as well as misconceptions concerning antibiotic effects in AOM, indicating that there is a need for more evidence-based information that improves parents' health literacy and enhances SDM in the treatment of children with AOM. Results on experiences with AOM therapy show that parental request rates for non-antibiotic options are in line with actual prescription rates, while antibiotics are three times less often requested by the parents than actually prescribed. This finding contradicts the hypothesis that parents put pressure on doctors to prescribe an antibiotic for their child with AOM. Further investigations are needed to clarify these findings.

\section{Additional file}

Additional file 1: Questionnaire (English translation).

\section{Abbreviations}

AOM: Acute otitis media; ENT specialist: Ear-nose-throat specialist; HI: Health insurance; SDM: Shared decision making.

\section{Competing interests}

The authors declare that they have no competing interests.

\section{Authors' contributions}

SKF was responsible for writing and completion of the first draft of the manuscript and prepared all tables and figures, contributed to the development, pretesting and revising of the questionnaire, and to the interpretation of the results. MR contributed to the completion of the manuscript and reviewed before submission. MR contributed to the development pretesting and revising of the questionnaire, and to the interpretation of the results. CS was responsible for the statistical data analyses. DC scanned and processed the questionnaires and contributed to preparing the statistical data analyses. SA contributed to the completion of the manuscript and reviewed manuscript before submission. SS contributed to the completion of the manuscript and reviewed manuscript before submission. All authors read and approved the final manuscript.

\section{Authors' information}

All authors are affiliated to the Institute for Health Economics and Clinical Epidemiology, University Hospital of Cologne and primarily work on health service research focusing on patient centeredness including health literacy, shared decision making and patient preferences. Mrs. Prof. Dr. med. Stephanie Stock is the chairwoman of the German Health Literacy Network and coordinates the network activities in Germany.

\section{Acknowledgements}

Parts of this work were supported by the AOK Bundesverband, Berlin, Germany. We thank Benjamin Scheckel for helping with table and figure adaption to the final manuscript. We thank Kristina Lorrek for helpful discussions for finalizing the manuscript. We thank Susanne Bassüner for organizational help performing the survey. We thank all childcare facilities that gave consent to participate and who considerably supported this survey by explaining and motivating parents to take part. We also thank all respondents for participation and thoroughly filling in the questionnaire.

\section{Author details}

${ }^{1}$ Institute of Health Economics and Clinical Epidemiology, University Hospital of Cologne (AöR), Gleueler Straße 176-178, 50935 Cologne, Germany. 
${ }^{2}$ Institute of General Practice, Medical Faculty, Heinrich-Heine-University Düsseldorf, Moorenstraße 5, 40225 Düsseldorf, Germany.

\section{Received: 29 January 2015 Accepted: 24 November 2015} Published online: 01 December 2015

\section{References}

1. Cober MP, Johnson CE. Otitis media: review of the 2004 treatment guidelines. Ann Pharmacother. 2005;39(11):1879-87.

2. Del Mar C, Glasziou P. A child with earache. Are antibiotics the best treatment? Aust Fam Physician. 2002;31(2):141-4

3. Leibovitz $\mathrm{E}$, Greenberg D. Acute otitis media in children: current epidemiology, microbiology, clinical manifestations, and treatment. Chang Gung Med J. 2004;27(7):475-88

4. Hansen MP, Jarbol DE, Gahrn-Hansen B, Depont Christensen R, Munck A, Ellegaard Trankjaer Ryborg C, et al. Treatment of acute otitis media in general practice: quality variations across countries. Fam Pract. 2011;29(1):63-8.

5. Teele DW, Klein JO, Rosner B. Epidemiology of otitis media during the first seven years of life in children in greater Boston: a prospective, cohort study. J Infect Dis. 1989;160(1):83-94.

6. Vergison A, Dagan R, Arguedas A, Bonhoeffer J, Cohen R, Dhooge I, et al. Otitis media and its consequences: beyond the earache. Lancet Infect Dis. 2010;10(3):195-203.

7. Kamtsiuris P, Atzpodien K, Ellert U, Schlack R, Schlaud M. Prevalence of somatic diseases in German children and adolescents. Results of the German Health Interview and Examination Survey for Children and Adolescents (KiGGS). Bundesgesundheitsblatt Gesundheitsforschung Gesundheitsschutz. 2007;50(5-6):686-700.

8. Vergison A. Microbiology of otitis media: a moving target. Vaccine. 2008;26 Suppl 7:G5-G10

9. Chonmaitree T, Ruohola A, Hendley JO. Presence of viral nucleic acids in the middle ear: acute otitis media pathogen or bystander? Pediatr Infect Dis J. 2012:31(4):325-30.

10. Coticchia JM, Chen M, Sachdeva L, Mutchnick S. New paradigms in the pathogenesis of otitis media in children. Front Pediatr. 2013;1:52.

11. Stockmann C, Ampofo K, Hersh AL, Carleton ST, Korgenski K, Sheng X, et al. Seasonality of acute otitis media and the role of respiratory viral activity in children. Pediatr Infect Dis J. 2013;32(4):314-9.

12. Thomas NM, Brook I. Otitis media: an update on current pharmacotherapy and future perspectives. Expert Opin Pharmacother. 2014;15(8):1069-83.

13. Pettigrew MM, Laufer AS, Gent JF, Kong Y, Fennie KP, Metlay JP. Upper respiratory tract microbial communities, acute otitis media pathogens, and antibiotic use in healthy and sick children. Appl Environ Microbiol. 2012;78(17): 6262-70.

14. Wiertsema SP, Kirkham LA, Corscadden KJ, Mowe EN, Bowman JM, Jacoby $P$, et al. Predominance of nontypeable Haemophilus influenzae in children with otitis media following introduction of a $3+0$ pneumococcal conjugate vaccine schedule. Vaccine. 2011:29(32):5163-70.

15. Pumarola F, Mares J, Losada I, Minguella I, Moraga F, Tarrago D, et al. Microbiology of bacteria causing recurrent acute otitis media (AOM) and AOM treatment failure in young children in Spain: shifting pathogens in the post-pneumococcal conjugate vaccination era. Int J Pediatr Otorhinolaryngol. 2013;77(8):1231-6.

16. Rosenfeld RM, Kay D. Natural history of untreated otitis media. Laryngoscope. 2003;113(10):1645-57.

17. Grijalva CG, Nuorti JP, Griffin MR. Antibiotic prescription rates for acute respiratory tract infections in US ambulatory settings. JAMA. 2009;302(7): 758-66.

18. Williamson I, Benge S, Mullee M, Little P. Consultations for middle ear disease, antibiotic prescribing and risk factors for reattendance: a case-linked cohort study. Br J Gen Pract. 2006;56(524):170-5.

19. Antimicrobial resistance: global report on surveillance http://www.who.int/ drugresistance/documents/surveillancereport/en/ Accessed 8 Jul 2014

20. Venekamp RP, Sanders S, Glasziou PP, Del Mar CB, Rovers MM. Antibiotics for acute otitis media in children. Cochrane Database Syst Rev. 2013;1, CD000219.

21. American Academy of Pediatrics Subcommittee on Management of Acute Otitis M. Diagnosis and management of acute otitis media. Pediatrics. 2004; 113(5):1451-65.

22. Lieberthal AS, Carroll AE, Chonmaitree T, Ganiats TG, Hoberman A, Jackson MA, et al. The diagnosis and management of acute otitis media. Pediatrics. 2013;131(3):e964-99.
23. Little P, Gould C, Williamson I, Moore M, Warner G, Dunleavey J. Pragmatic randomised controlled trial of two prescribing strategies for childhood acute otitis media. BMJ. 2001;322(7282):336-42.

24. Rovers MM, Glasziou P, Appelman CL, Burke P, McCormick DP, Damoiseaux RA, et al. Antibiotics for acute otitis media: a meta-analysis with individual patient data. Lancet. 2006;368(9545):1429-35.

25. Toll EC, Nunez DA. Diagnosis and treatment of acute otitis media: review. Laryngol Otol. 2012;126(10):976-83.

26. McGrath LJ, Becker-Dreps S, Pate V, Brookhart MA. Trends in antibiotic treatment of acute otitis media and treatment failure in children, 2000-2011. PLoS One. 2013;8(12), e81210.

27. Haggard M. Poor adherence to antibiotic prescribing guidelines in acute otitis media-obstacles, implications, and possible solutions. Eur J Pediatr. 2011;170(3):323-32.

28. Milandri M, Moro ML, Marchi M. Antibiotic prescribing for upper respiratory tract infections in children: the role of parental expectations. J Pediatr. 2005; 147(5):714. author reply 714-715.

29. Moro ML, Marchi M, Gagliotti C, Di Mario S, Resi D, "Progetto Bambini a Antibiotici" Regional G. Why do paediatricians prescribe antibiotics? Results of an Italian regional project. BMC Pediatr. 2009;9:69.

30. Kuzujanakis M, Kleinman K, Rifas-Shiman S, Finkelstein JA. Correlates of parental antibiotic knowledge, demand, and reported use. Ambul Pediatr. 2003;3(4):203-10.

31. Stivers T, Mangione-Smith R, Elliott MN, McDonald L, Heritage J. Why do physicians think parents expect antibiotics? What parents report vs what physicians believe. J Fam Pract. 2003;52(2):140-8

32. Finkelstein JA, Stille CJ, Rifas-Shiman SL, Goldmann D. Watchful waiting for acute otitis media: are parents and physicians ready? Pediatrics. 2005;115(6): 1466-73.

33. Yin HS, Dreyer BP, Vivar KL, MacFarland S, van Schaick L, Mendelsohn AL. Perceived barriers to care and attitudes towards shared decision-making among low socioeconomic status parents: role of health literacy. Academic Pediatrics. 2012;12(2):117-24.

34. Merenstein D, Diener-West M, Krist A, Pinneger M, Cooper LA. An assessment of the shared-decision model in parents of children with acute otitis media. Pediatrics. 2005:116(6):1267-75.

35. Bortz J. Statistik für Sozialwissenschaftler. Berlin: Springer; 1999.

36. Bortz JDN. Forschungsmethoden und Evaluation für Sozialwissenschaftler. Berlin: Springer; 1995.

37. Jónsson $\mathrm{H}$, Haraldsson $\mathrm{RH}$. Parents' perspectives on otitis media and antibiotics. A qualitative study. Scand J Prim Health Care. 2002;20(1):35-9.

38. Forsyth B, Lessler J. Cognitive Laboratory Methods: A Taxonomy. In: Biemer P, editor. Measurement Errors in Surveys. New York: John Wiley; 1991.

39. Fonteyn ME, Kuipers B, Grobe SJ. A Description of Think Aloud Method and Protocol Analysis. Qual Health Res. 1993:3.

40. Schwarz N, Sudman S. Answering questions: methodology for determining cognitive and communicative processes in survey research: Wiley. 1995

41. Prüfer P, Rexroth M. ZUMA Arbeitsbericht 2000/08. 2-Phasen-Pretesting. Mannheim: ZUMA; 2000.

42. Likert R. A technique for the measurement of attitudes. 1932. p. 55.

43. Porst R. Question Wording-Zur Formulierung von Fragebogen-Fragen. In: ZUMA How-to-Reihe, Nr 2. edn.: GESIS; 2000

44. Mummendy HD: Die Fragebogen-Methode. Hogrefe; 2003.

45. Abu-Baker NN, Gharaibeh HF, Al-Zoubi HM, Savage C, Gharaibeh MK Mothers' knowledge and practices of managing minor illnesses of children under five years. J Res Nurs. 2012;18(7):651-66.

46. Nokso-Koivisto J, Hovi T, Pitkaranta A. Viral upper respiratory tract infections in young children with emphasis on acute otitis media. Int J Pediatr Otorhinolaryngol. 2006;70(8):1333-42.

47. Thomas JP, Berner R, Zahnert T, Dazert S. Strukturiertes Vorgehen bei akuter Otitis media. 2014

48. McNulty CA, Boyle P, Nichols T, Clappison P, Davey P. Don't wear me out-the public's knowledge of and attitudes to antibiotic use. J Antimicrob Chemother. 2007:59(4):727-38.

49. Finkelstein JA, Dutta-Linn M, Meyer R, Goldman R. Childhood infections, antibiotics, and resistance: what are parents saying now? Clin Pediatr (Phila). 2014:53(2):145-50.

50. Sidell D, Shapiro NL, Bhattacharyya N. Demographic influences on antibiotic prescribing for pediatric acute otitis media. Otolaryngol Head Neck Surg. 2012;146(4):653-8 
51. Barber $\mathrm{C}$, Ille $\mathrm{S}$, Vergison A, Coates $\mathrm{H}$. Acute otitis media in young children-what do parents say? Int J Pediatr Otorhinolaryngol. 2014;78(2): 300-6.

52. Tahtinen PA, Boonacker CW, Rovers MM, Schilder AG, Huovinen P, Liuksila $P R$, et al. Parental experiences and attitudes regarding the management of acute otitis media-a comparative questionnaire between Finland and The Netherlands. Fam Pract. 2009;26(6):488-92.

53. Panagakou SG, Spyridis N, Papaevangelou V, Theodoridou KM, Goutziana GP, Theodoridou MN, et al. Antibiotic use for upper respiratory tract infections in children: a cross-sectional survey of knowledge, attitudes, and practices (KAP) of parents in Greece. BMC Pediatr. 2011;11:60.

54. Dube E, De Wals P, Gilca V, Boulianne N, Ouakki M, Lavoie F, et al. Burden of acute otitis media on Canadian families. Can Fam Physician. 2011;57(1):60-5.

55. Glaeske G, Hoffmann F, Koller D, Tholen K, Windt R. Faktencheck Gesundheit Antibiotika-Verordnungen bei Kindern. 2012.

56. Andre M, Vernby A, Berg J, Lundborg CS. A survey of public knowledge and awareness related to antibiotic use and resistance in Sweden. J Antimicrob Chemother. 2009;65(6):1292-6.

57. ISEG Institut für Sozialmedizin EuG. BARMER GEK Arztreport 2012. 2012

58. Pshetizky Y, Naimer S, Shvartzman P. Acute otitis media-a brief explanation to parents and antibiotic use. Fam Pract. 2003;20(4):417-9.

59. Chao JH, Kunkov S, Reyes LB, Lichten S, Crain EF. Comparison of two approaches to observation therapy for acute otitis media in the emergency department. Pediatrics. 2008;121(5):e1352-6.

60. Lee HJ, Park SK, Choi KY, Park SE, Chun YM, Kim KS, et al. Korean clinical practice guidelines: otitis media in children. J Korean Med Sci. 2012;27(8): 835-48.

61. Marchisio P, Bellussi L, Di Mauro G, Doria M, Felisati G, Longhi R, et al. Acute otitis media: From diagnosis to prevention. Summary of the Italian guideline. Int J Pediatr Otorhinolaryngol. 2010;74(11):1209-16.

62. Minovi A, Dazert S. [Diseases of the middle ear in childhood]. Laryngorhino- otologie. 2014;93 Suppl 1:S1-S23.

63. Rousounidis A, Papaevangelou V, Hadjipanayis A, Panagakou S, Theodoridou M, Syrogiannopoulos G, et al. Descriptive study on parents' knowledge, attitudes and practices on antibiotic use and misuse in children with upper respiratory tract infections in Cyprus. Int J Environ Res Public Health. 2011; 8(8):3246-62.

64. Palmer DA, Bauchner H. Parents' and physicians' views on antibiotics. Pediatrics. 1997;99(6), E6.

65. Falk B-HLWFVTPHCLHKMHTAG-CMF-VPYM. Trust, openness and continuity of care influence acceptance of antibiotics for children with respiratory tract infections: a four country qualitative study. Fam Pract. 2014;31(1):102-10.

66. Lopez-Vazquez P, Vazquez-Lago JM, Figueiras A. Misprescription of antibiotics in primary care: a critical systematic review of its determinants. J Eval Clin Pract. 2012;18(2):473-84.

67. Blomgren K, Pitkaranta A. Is it possible to diagnose acute otitis media accurately in primary health care? Fam Pract. 2003;20(5):524-7.

68. Blomgren K, Pitkaranta A. Current challenges in diagnosis of acute otitis media. Int J Pediatr Otorhinolaryngol. 2005;69(3):295-9.

69. Lieberthal AS. Revised AOM guideline emphasizes accurate diagnosis. 2013. p. 34.

70. de Bont EG, Francis NA, Dinant GJ, Cals JW. Parents' knowledge, attitudes, and practice in childhood fever: an internet-based survey. Br J Gen Pract. 2014;64(618):e10-6.

71. Napolitano F, Izzo MT, Di Giuseppe G, Angelillo IF. Public knowledge, attitudes, and experience regarding the use of antibiotics in Italy. PLoS One. 2013;8(12), e84177.

72. Vinker $\mathrm{S}$, Ron A, Kitai E. The knowledge and expectations of parents about the role of antibiotic treatment in upper respiratory tract infection-a survey among parents attending the primary physician with their sick child. BMC Fam Pract. 2003:4:20

\section{Submit your next manuscript to BioMed Central and we will help you at every step:}

- We accept pre-submission inquiries

- Our selector tool helps you to find the most relevant journal

- We provide round the clock customer support

- Convenient online submission

- Thorough peer review

- Inclusion in PubMed and all major indexing services

- Maximum visibility for your research

Submit your manuscript at www.biomedcentral.com/submit 